\section{International Scientific Journal Theoretical \& Applied Science}

\author{
p-ISSN: 2308-4944 (print) e-ISSN: 2409-0085 (online) \\ Year: 2014 Issue: 12 Volume: 20 \\ Published: $30.12 .2014 \quad$ http://www.T-Science.org
}

SECTION 7. Mechanics and machine construction.
Denis Alexandrovich Chemezov

Master of Engineering and Technology, Lecturer of Vladimir Industrial College, Russia chemezov-da@yandex.ru

Svetlana Ivanovna Tyurina Lecturer of Vladimir Industrial College, Russia swetl.tyurina2015@yandex.ru

Anzhelika Vladimirovna Bayakina Lecturer of Vladimir Industrial College, Russia bajakina.anzhelika@yandex.ru

Vladimir Vladimirovich Goremykin Student of Vladimir Industrial College, Russia vladimir_goremykin@mail.ru

\title{
FLUID TRANSIENTS FLOW IN PIPING ELBOW
}

Abstract: The article describes the process of transition from laminar to turbulent flow of water in the elbows of the different pipeline configurations. Based on a critical analysis of computer simulation results, the optimal overall dimensions of the elbow of the pipeline in which there is the least turbulent flow have been defined.

Key words: piping elbow, the rate of fluid flow, bending radius, laminar and turbulent fluid flows.

Language: Russian

Citation: Chemezov DA, Tyurina SI, Bayakina AV, Goremykin VV (2014) FLUID TRANSIENTS FLOW IN PIPING ELBOW. ISJ Theoretical \& Applied Science 12 (20): 4-8. http://dx.doi.org/10.15863/TAS.2014.12.20.2

\section{УДК 621.64}

\section{ПЕРЕХОДНЫЕ ПРОЦЕССЫ ТЕЧЕНИЯ ЖИДКОСТИ В КОЛЕНЕ ТРУБОПРОВОДА}

Аннотация: В статье дано описание прочесса перехода ламинарного течения воды в турбулентное 8 коленах трубопровода различных конфигурачий. На основании критического анализа результатов компьютерного моделирования, определены оптимальные габаритные размеры колена трубопровода, при которых наблюдается наименьший турбулентный поток.

Ключевые слова: колено трубопровода, скорость течения жидкости, радиус изгиба, ламинарное и турбулентное течения жидкости.

Перемещение на расстояния жидкостей различного назначения под давлением, осуществляется по трубопроводам. Основными показателями эффективного использования трубопроводов является поддержание постоянного или увеличение расхода (а соответственно и давления) жидкости. Переменные внутренние диаметры и изменение направления продольной оси (изгиб) трубопровода, трение жидкости о стенку трубы, увеличение температуры и др. приводят к изменению характера течения потоков жидкости - от ламинарного в турбулентное, тем самым снижаются средние скорости течения жидкости и в результате уменьшается расход [1].

Ламинарное течение наблюдается при небольших скоростях жидкости, при этом слои жидкости не перемешиваются между собой. С увеличением скорости течения жидкости (например, течение жидкости в конфузоре, диффузоре [2] или изогнутом колене трубопровода) характер течения жидкости изменяется на турбулентный - возникают вихревые потоки, способствующие перемешиванию жидкости [3]. Хаотичное направление течения жидкости турбулентного потока в этот момент будет наблюдаться по всей площади сечения трубы, тем самым снижается средняя скорость жидкости в продольном направлении. По мере удаления от места турбулентного потока, течение жидкости будет переходить в ламинарное.

Цель исследования - определение характера течения жидкости в прямолинейных и изогнутых частях трубопровода и выбор оптимальной 
конфигурации колена с учетом наименьшей потери давления на выходе.

Исследование выполнялось в программе Ansys CFX [4]. Моделировалось течение воды с начальной скоростью $3 \mathrm{~m} / \mathrm{c}$ в коленах трубопроводов без радиуса и с радиусами изгиба
$\mathrm{R}_{\text {изг. }}=32,5$ мм, $\mathrm{R}_{\text {изг. }}=42,5$ мм и $\mathrm{R}_{\text {изг. }}=57,5$ мм в условии устойчивого состояния системы (без возмущений). Материал модели колена конструкционная сталь. Габаритные размеры твердотельных моделей колен трубопроводов представлены на рис. 1.

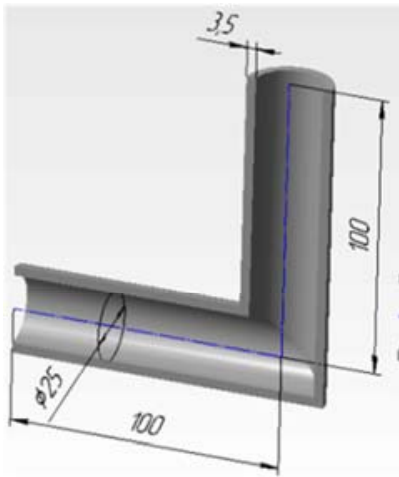

a) б)

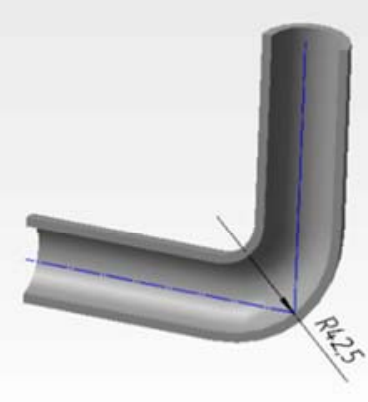

B)

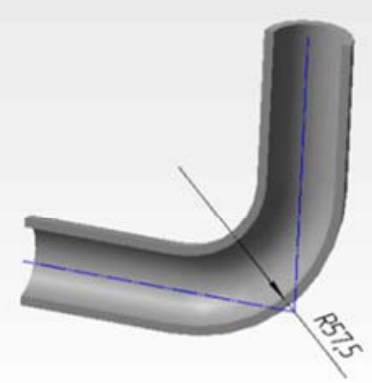

г)

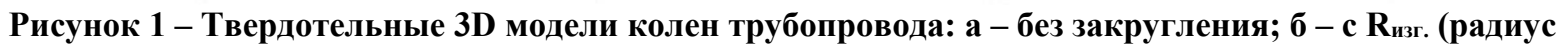
изгиба) $=32,5$ мм; в - с $R_{\text {изг. }}=42,5$ мм; г - с $R_{\text {изг. }}=57,5$ мм

По условию поставленной задачи, вода без примесей, под давлением 1 атм. непрерывно поступает во входное отверстие трубы и истекает из выходного отверстия в дозвуковом режиме [5]. Температура воды составила $25^{\circ} \mathrm{C}$. Остальные свойства воды, принятые для моделирования, представлены в табл. 1.

Таблица 1

\begin{tabular}{|c|c|}
\hline \multicolumn{2}{|c|}{ Свойства воды } \\
\hline Параметр & Значение \\
\hline Молярная масса & 18,02 кг/кмоль \\
\hline Удельная теплоемкость & $4181,7$ Дж/(кг $\times$ К $)$ \\
\hline Теплопроводность & $0,6069 \mathrm{BT} /(\mathrm{M} \times \mathrm{K})$ \\
\hline
\end{tabular}

\begin{tabular}{|c|c|}
\hline Тепловая расширяемость & $2,57 \times 10^{-4} \mathrm{~K}^{-1}$ \\
\hline Показатель преломления & $1 \mathrm{M} / \mathrm{M}$ \\
\hline Показатель поглощения & $1 \mathrm{M}$ \\
\hline Динамическая вязкость & $8,9 \times 10^{-4} \mathrm{\kappa г}(\mathrm{M} \times \mathrm{c})$ \\
\hline
\end{tabular}

Процесс происходил при изотермическом теплообмене.

Моделирование турбулентных потоков жидкости производилось по модели k-Epsilon при средней интенсивности [6].

Результаты моделирования представлены в виде эпюр направления и величин скоростей течения воды в коленах трубопровода (рис.2-5).

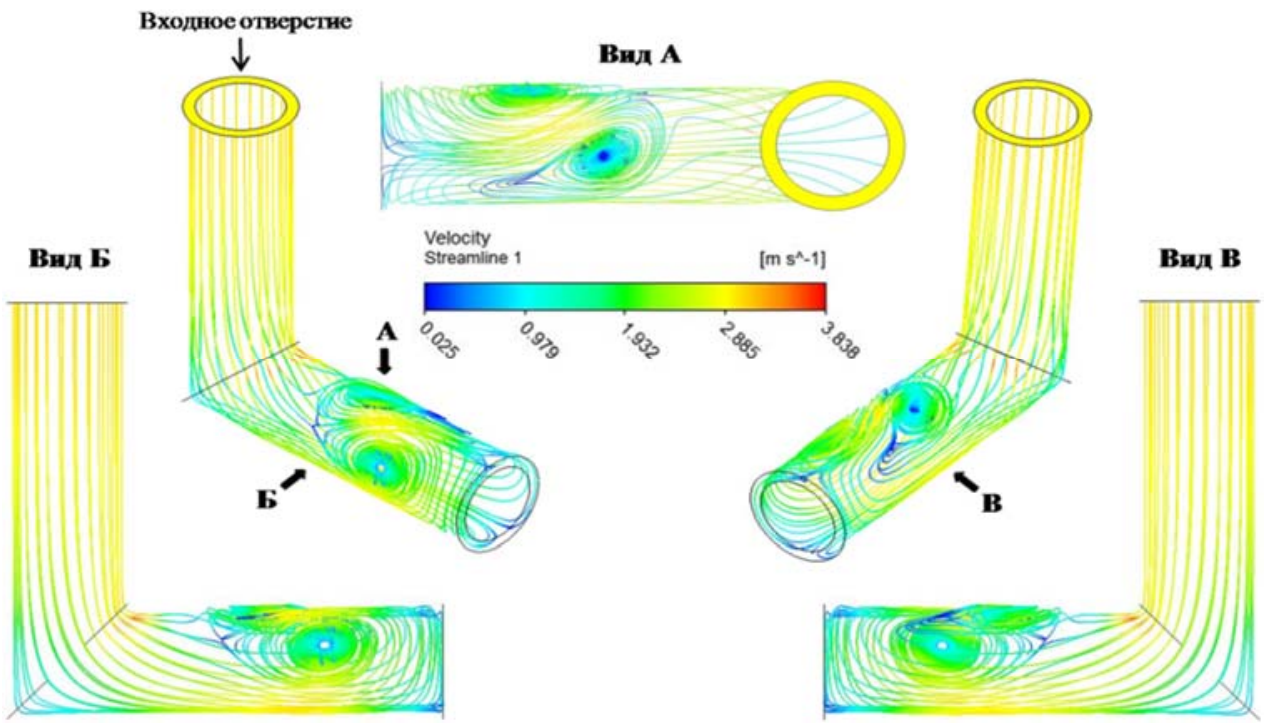

Рисунок 2 - Эпюра скоростей течения воды в колене трубопровода без радиуса изгиба.

ISPC European Research, Birmingham, United Kingdom 


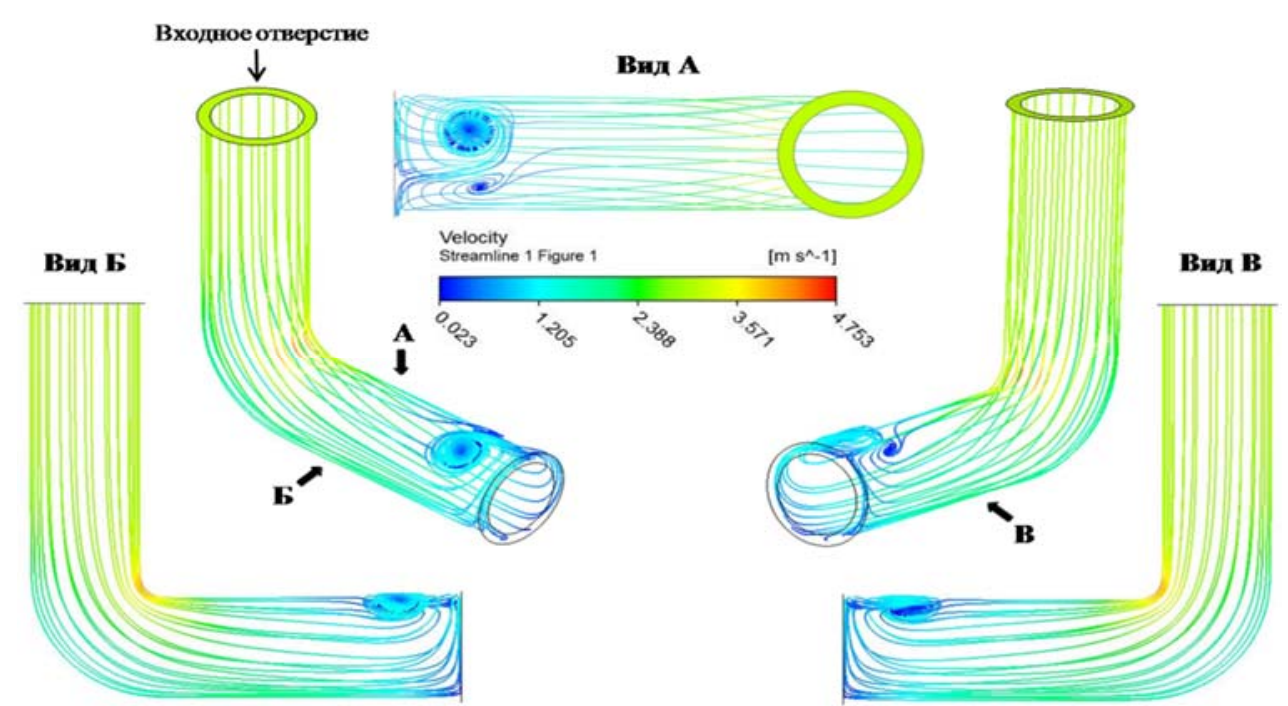

Рисунок 3 - Эпюра скоростей течения воды в колене трубопровода с $\mathbf{R}_{\text {изг. }}=32,5$ мм.

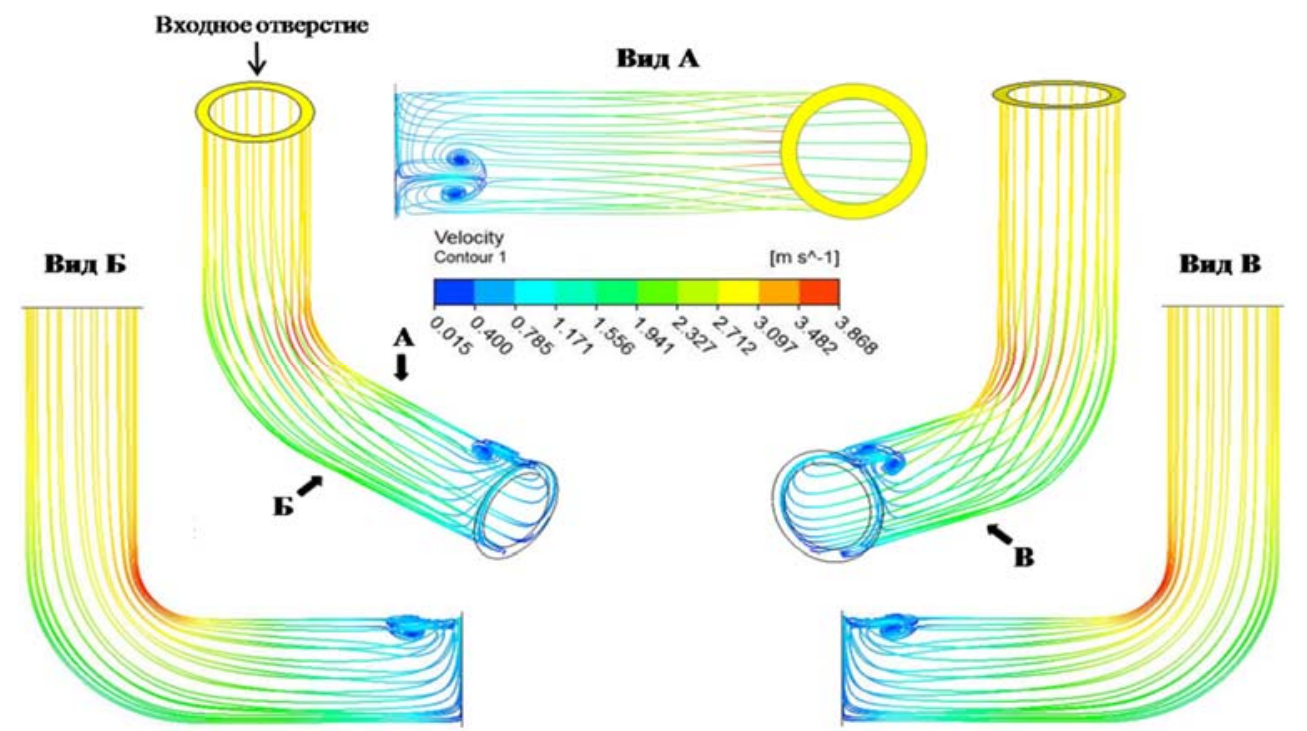

Рисунок 4 - Эпюра скоростей течения воды в колене трубопровода с $R_{\text {изг. }}=42,5$ мм.

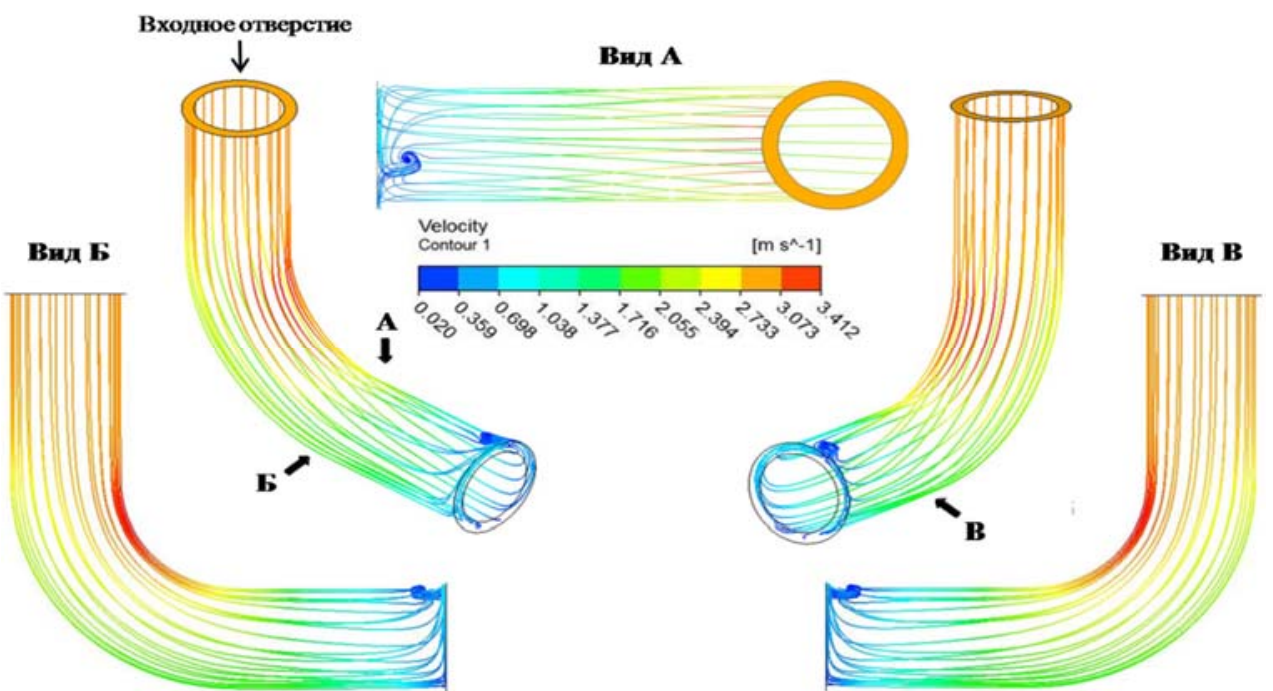

Рисунок 5 - Эпюра скоростей течения воды в колене трубопровода с $R_{\text {изг. }}=57,5$ мм

ISPC European Research, 
Для колена без радиуса изгиба, характер течения жидкости будет переменным на разных участках трубопровода. Вода поступает в вертикальный прямолинейный участок колена с начальной скоростью. Течение жидкости ламинарное. В месте соединения вертикальной и горизонтальной трубы, поток воды меняет свое направление и скорость. Происходит плавный поворот струи по радиусу и уменьшение скорости течения жидкости до 1,2 м/с у наружного угла изгиба трубопровода. У внутреннего угла, резкий поворот струи с увеличением скорости течения жидкости до 3,72 м/с. На входе в горизонтальную трубу, потоки воды с разными скоростями смешиваются друг с другом, и на длине примерно 75 - 80 мм начинают закручиваться, поднимаясь вверх. Происходит переход ламинарного течения жидкости в турбулентное. В момент образования вихреобразных областей и при приближении к центру турбулентного потока отмечается изменение скорости течения жидкости с 2,9 до $0,1 \mathrm{~m} / \mathrm{c}$.

Течение воды в колене трубопровода с радиусом изгиба, имеет более упорядоченный характер. Наблюдается плавное изменение направления течения жидкости у внешнего и внутреннего радиусах изгиба трубопровода. Разность скоростей течения воды на участке изгиба колена будет уменьшаться при увеличении радиуса (табл. 2).

Таблица 2

Соотношение скоростей течения воды на $\mathbf{R}_{\text {изг. }}$

\begin{tabular}{|c|c|c|}
\hline $\begin{array}{c}\mathrm{R}_{\text {изг. }} \\
\text { колена, } \\
\text { мм }\end{array}$ & $\begin{array}{c}\text { Скорость } \\
\text { течения воды } \\
\text { у внутр. } \mathrm{R}_{\text {изг. }}\end{array}$ & $\begin{array}{c}\text { Скорость } \\
\text { течения воды } \\
\text { у наруж. } \mathrm{R}_{\text {изг. }} \mathrm{M} / \mathrm{c}\end{array}$ \\
\hline 32,5 & 4,5 & 1,2 \\
\hline 42,5 & 3,87 & 2,0 \\
\hline 57,5 & 3,4 & 2,4 \\
\hline
\end{tabular}

В соответствии с эпюрами, можно отметить, что интенсивность и объем турбулентного течения воды будут наименьшими на выходе колена трубопровода с $\mathrm{R}_{\text {изг. }}=57,5 \mathrm{Mм}$.

Давление и скорость течения воды будут изменяться на участке трубопровода имеющего некоторый радиус изгиба. При этом градиент давления [7] компенсирует центробежную силу, которая будет направлена на внутренний угол радиуса изгиба трубопровода $R_{b e n d}$.

$$
\frac{m v^{2}}{R_{\text {bend }}}=\operatorname{grad} P,
$$

где $m=\rho V-$ масса воды, кг; $v-$ средняя скорость течения жидкости на изогнутом участке трубопровода, м/с; $\rho$ (плотность воды) $=997$ кг $/ \mathrm{M}^{3} ; \quad V$ - объем участка изгиба колена заполненный водой, ${ }^{3} ; P$ - давление, Па.

Вследствие чего, на внутреннем угле изгиба колена давление становится меньше [8].

На основании полученных результатов имитационного моделирования течения воды в коленах трубопровода, можно сделать следующие выводы:

1) одним из факторов возникновения турбулентного потока, является изменение скоростей течения воды по всей площади сечения трубопровода на участке (радиуса) изгиба;

2) уменьшение значения перепада давлений в изогнутой части трубопровода обеспечивается увеличением величины радиуса изгиба (в данном случае $\mathrm{R}_{\text {изг. }}=57,5$ мм), что и должно предусматриваться при выборе оптимальной конфигурации колена, которая обеспечивает наибольшую производительность транспортирования жидкости.

\section{References:}

1. (2014) Viazkost'. Laminarnye i turbulentnye rejimy techenia. Available:

http://www.terver.ru/Vjazkost Laminarnoe tur bulentnoe techenie.php

(Accessed: 12.12.2014).

2. Chemezov DA, Bayakina AV (2014) Simulation modeling of water flow in the Venturi nozzle. ISJ Theoretical \& Applied
Science 07 (15): 25-29. doi: http://dx.doi.org/10.15863/TAS.2014.07.15.4

3. (2014) Turbulentnoe dvijenie jidkosti. Available: $\quad$ http://hydraulic-drive.ru/lektsiigidravlika/97-turbulentnoe-dvizheniezhidkosti.html (Accessed: 12.12.2014).

4. (2014) Opisanie arhitektury i processa reshenia zadach posredstvom paketa ANSYS CFX. Available: 
http://supercomputer.susu.ac.ru/users/instructio ns/cfx arch/ (Accessed: 12.12.2014).

5. (2014) Dozvukovoe techenie. Available: http://www.aircaft.ru/aviationencyclopedia/d/1205-dozvukovoe-techenie.html (Accessed: 12.12.2014).

6. (2014) Modeli turbulentnosti, dostupnye V programme ANSYS CFX. Available: http://cfdhelper.ru/model/model_cfxmod.html (Accessed: 12.12.2014).
7. (2014) Gradient davlenia. Available: http://chem21.info/info/131128/ (Accessed: 12.12.2014).

8. (2014) Uravnenie Bernulli dlya potoka real'noy jidkosti. Available: http://hydraulicdrive.ru/osnovy-gidravliki/338-uravneniebernulli-dlja-potoka-realnoj-zhidkosti $3 . \mathrm{html}$ (Accessed: 12.12.2014.) 